\title{
Genome-Wide Transcriptomic Analysis of N-Caproic Acid Production in Ruminococcaceae Bacterium CPB6 with Lactate Supplementation
}

\section{YONG TAO ( $\boldsymbol{\nabla}$ taoyong@cib.ac.cn )}

Chengdu Institute of Biology, Chinese Academy of Sciences https://orcid.org/0000-0001-8523-9122

Shaowen Lu

Chendu Institute of Biology, Chinese Academy of Sciences

Yi Wang

Department of Biosystems Engineering, Auburn University

Cuicui Wei

Chengdu Branch National Science Library Chinese Academy of Sciences

\section{Research}

Keywords: n-Caproic acid, Lactate, Chain elongation, Transcriptome, RNA-Seq

Posted Date: April 27th, 2020

DOl: https://doi.org/10.21203/rs.3.rs-23672/v1

License: (c) (i) This work is licensed under a Creative Commons Attribution 4.0 International License. Read Full License 


\section{Abstract}

Background: $\mathrm{n}$-Caproic acid (CA) is gaining increased attention due to its high value as a chemical feedstock. Our recent studies have demonstrated that lactate can be an attractive energy substrate for the production of CA. However, little is known about the potential molecular mechanism for CA production triggered by the supplementation of exogenous lactate at the gene transcriptional level.

Results: $5 \%$ lactate was supplemented into the fermentation with Ruminococcaceae bacterium CPB6 for CA production. Results showed that lactate supplementation led to earlier CA production and higher final CA titer and productivity. Transcriptional analysis was carried out using RNA-Seq for the culture with lactate supplementation compared to the control (without lactate supplementation). It has been indicated that there were only 34 differentially expressed genes (DEGs) between the two groups at the exponential phase, of which 15 were upregulated, and 19 were downregulated by more than two-fold. A total of 245 DEGs were identified between the two groups at the stationary phase, of which 123 were upregulated and 122 were downregulated. These DEGs cover crucial functional categories. Specifically, 5 genes responsible for the reverse $\beta$-oxidation pathway, 11 genes encoding ATP-binding cassette (ABC) transporters, 6 genes encoding substrate-binding protein (SBP) and 4 genes encoding phosphotransferase system (PTS) transporters were strikingly upregulated in response to the addition of lactate. These genes would be candidates for future studies aiming at understanding the regulatory mechanism of lactate conversion into CA, as well as for the improvement of CA production in strain CPB6.

Conclusion: This study suggested that lactate supplementation can promote CA production by altering the expression patterns of genes involved in the essential metabolic pathways, such as central pyruvate metabolism, the reverse $\beta$-oxidation pathway, ABC and PTS transports. The findings presented herein reveal unique insights into the biomolecular effects of lactate on CA production at the gene transcriptional level.

\section{Background}

The increasing demand for fuels and chemicals and the scarcity of fossil resources necessitate the development of sustainable and innovative strategies for the industrial production. Organic residual streams (e.g., food waste and brewery wastewater) have great potential to be employed as feedstock for the production of biofuels and biochemicals [1, 2].

$n$-Caproic acid (CA) is a medium chain fatty acid of 6 -carbon, which has recently gained considerable attention due to its high value as a fuel and chemical feedstock [3]. Biosynthesis of CA can be achieved in some anaerobic bacteria (e.g., Clostridium kluyveri) via the chain elongation pathway with ethanol as reduced substrate (electron donor) [4,5], in which the oxidation of ethanol provides energy and acetyl-CoA for the reverse $\beta$-oxidation pathway [6]. Many studies show that the addition of ethanol during the acidification of wastes can promote chain elongation, and lead to higher volumetric production rates and a high CA selectivity [7, 8], indicating that ethanol is an efficient reduced substrate for CA production. In addition, researchers explore other chemicals used as electron donors for CA production, including hydrogen [9], methanol [10], propanol [11], and D-galactitol [12], but the yield of CA from these substrates is much lower than that from ethanol.

Recently, lactate was showed to be a potential alternative to ethanol for the production of CA by reactor microbiome systems [13, 14]. Furthermore, our study demonstrates that CA is efficiently produced from lactate by the pure culture of a Ruminococcaceae bacterium CPB6 [15]. Moreover, strain CPB6 can produce CA (C6) from lactate (as electron donor) with C2-C4 carboxylic acids as electron acceptors, and heptoic acid (C7) with C3-C5 carboxylic acids [16]. More recently, we identified sets of genes correlated with the chain elongation pathway by sequencing and annotating the whole genome of the CPB6 strain [17]. However, the detailed molecular mechanism of lactate conversion into CA still remains unknown, and there is no genome-wide transcriptomic analysis of the CPB6 strain concerning its metabolism for CA production using lactate as the electron donor. This makes it impossible to clarify the effect of lactate on the metabolic pathway shift for CA production at the molecular level.

RNA-Seq is a powerful method to elucidate the metabolism and identify specific genes/enzymes for the particular interesting metabolic pathways [18, 19]. In the present study, RNA-Seq for the transcriptomic analysis of strain CPB6 was carried out to investigate the effect of lactate

supplementation on cell growth, CA production and other essential metabolisms. The identified key genes herein provide candidates for the metabolic engineering in the future in order to develop more robust strains based on CPB6 for enhanced production of CA and relevant biochemicals.

\section{Results And Discussion}

\section{Growth and fermentation kinetics}

As shown in Figure 1a, cells took approximately $12 \mathrm{~h}$ to grow to the exponential phase and $18 \mathrm{~h}$ to grow to the stationary phase. Although the maximum OD600 of the culture with lactate supplementation was slightly higher than that of the control (without lactate supplementation) at the stationary phase (1.25 vs 1.16), both cultures showed similar growth kinetics, indicating that lactate supplementation had little impact on cell growth. The CA production was started to be observed in the culture with lactate supplementation after $6 \mathrm{~h}$ of cultivation, and the CA titer continued to increase and reached $1717.2 \mathrm{mg} \mathrm{L}-1$ at $21 \mathrm{~h}$ (Figure $1 \mathrm{~b}$ ), while CA production was not detected until $15 \mathrm{~h}$ of cultivation in the control, the CA titer of which only reached $618 \mathrm{mg} \mathrm{L-1}$ at $21 \mathrm{~h}$. In both cultures, while more significantly in the culture with lactate supplementation, the main endproduct was CA together with small amount of butyrate, suggesting that the carbon flux of acetyl-CoA may be inclined to be channelled to CA synthesis, especially in the presence of lactate. This is consistent with our previous studies [15].

In sum, the lactate supplementation had little effect on the cell growth, but led to earlier initiation for CA production ( 6 vs $15 \mathrm{~h}$ ), higher final CA titer ( 1717 vs $618 \mathrm{mg} \mathrm{L}-1)$ and higher CA productivity (81.8 vs $29.4 \mathrm{mg} \mathrm{L-1} \mathrm{h-1).}$ 


\section{RNA-Seq statistics}

Samples were taken for RNA-Seq analysis from both the exponential (12h) and stationary (18h) phases for both the culture with lactate supplementation and the control. For each culture, independent biological triplicates $(a, b$, and $c)$ were included (Table 1). Therefore, a total of twelve samples were taken for cDNA libraries construction and sequencing on the Illumina HiSeq platform (Illumina, San Diego, USA). The number of raw reads generated from the sequencing for each library was from 15.7 to 23.5 million (Table S1 in Additional files). A total of $224 \mathrm{Mb}$ sequence reads from 12 cDNA libraries were mapped to the genome of strain CPB6. Only those reads that mapped unambiguously to the CPB6 genome were used for further analysis.

Table 1

Summary of RNA-Seq sequencing and data analysis results Sample Name

\begin{tabular}{|c|c|c|c|c|c|c|c|c|c|c|c|}
\hline \multicolumn{3}{|c|}{ Sample Name } & \multicolumn{2}{|l|}{ L1 } & \multicolumn{2}{|l|}{ L2 } & \multicolumn{2}{|r|}{$\mathrm{C} 1$} & \multicolumn{3}{|c|}{$\mathrm{C} 2$} \\
\hline a & b & & a & b & c & a & & c & a & b & \\
\hline $\begin{array}{l}\text { Total } \\
\text { reads }\end{array}$ & 22982792 & 18614536 & 18087962 & 16881648 & 16844058 & 15343814 & 18684112 & 19108148 & 19099082 & 19909258 & 23 \\
\hline $\begin{array}{l}\text { No. of } \\
\text { read } \\
\text { mapped }\end{array}$ & 22684858 & 18390709 & 17865180 & 16713319 & 16606726 & 15098988 & 18437261 & 18893873 & 18905208 & 19631686 & 22 \\
\hline $\begin{array}{l}\text { Ratio of } \\
\text { reads } \\
\text { mapped } \\
(\%)\end{array}$ & 98.7 & 98.8 & 98.77 & 99 & 98.59 & 98.4 & 98.68 & 98.88 & 98.98 & 98.61 & 98 \\
\hline $\begin{array}{l}\text { No. of } \\
\text { unique } \\
\text { reads } \\
\text { mapped }\end{array}$ & 22339068 & 17915954 & 17559600 & 16540060 & 16324768 & 14862898 & 18050316 & 18505697 & 18508661 & 19247256 & 22 \\
\hline $\begin{array}{l}\text { No. of } \\
\text { genes with } \\
\text { detectable } \\
\text { expression }\end{array}$ & 1969 & 1968 & 1968 & 1968 & 1969 & 1968 & 1968 & 1968 & 1968 & 1968 & 19 \\
\hline $\begin{array}{l}\text { Range in } \\
\text { expression } \\
\text { levels } \\
\text { (TPM) }\end{array}$ & $\begin{array}{l}8.3- \\
2.7 \times 104\end{array}$ & $\begin{array}{l}8.0- \\
1.7 \times 104\end{array}$ & $\begin{array}{l}11.5- \\
1.7 \times 104\end{array}$ & $\begin{array}{l}3.2- \\
5.3 \times 104\end{array}$ & $\begin{array}{l}26.4 \\
-3.7 \times 104\end{array}$ & $6.6-7.3 \times 104$ & $\begin{array}{l}4.3- \\
2.0 \times 104\end{array}$ & $\begin{array}{l}3.8- \\
1.8 \times 104\end{array}$ & $\begin{array}{l}4.1- \\
1.9 \times 104\end{array}$ & $\begin{array}{l}5.2- \\
2.4 \times 104\end{array}$ & $\begin{array}{l}10 \\
1 . \varepsilon\end{array}$ \\
\hline
\end{tabular}

L1: cell culture with lactate supplementation from the exponential phase;

L2: cell culture with lactate supplementation from the stationary phase;

C1: Control culture without lactate supplementation from the exponential phase;

C2: Control culture without lactate supplementation from the stationary phase.

$\mathrm{a}, \mathrm{b}$ and $\mathrm{c}$ represented the biological triplicate samples.

Overall, out of reads derived from all the samples, 15.1 to 22.7 million reads were unambiguously mapped to the CPB6 genome, and over $98 \%$ reads were mapped (Table 1). A total of 1968/1969 out of 2045 protein-coding genes had detectable expression in both conditions (with or without lactate supplementation) (Table 1), indicating that the RNA-Seq analysis in this study achieved comprehensive coverage of the CPB6 transcriptome. The transcription levels (the number of transcripts per million, TPM) of most active protein-coding genes were in the range of $3.2 \times 104-7.3 \times 104$.

As illustrated in Figure 2, the gene expression could be classified into four levels: low (TPM<30), moderate (TPM: 30-150), high (TPM: 150-1000), and very high $(T P M>1000)$. The number of genes at some specific expression levels was significantly different for the two cultures (with or without lactate supplementation). For the exponential phase, there were slightly more genes in the moderate and high and very high expression level in the culture with lactate supplementation than in the control, but lowly expressed genes were significantly decreased. While for the stationary phase, the culture with lactate supplementation had more genes in the moderate expression level, but fewer genes in the high and very high expression level. These results suggested that more changes in gene expression are triggered by the addition of lactate at the stationary phases.

\section{Functional annotation and classification}

In the transcriptome of strain CPB6, a total of 1122 expressed genes were allocated into three primary Gene Ontology (GO) categories (Figure 3 ), including the category of biological process (601 genes), cellular component (524 genes), and molecular function (916 genes). In each category, the genes were further assigned into 28 functional groups, such as metabolic process (478 genes), cellular process (440 genes), cell part (307 genes), membrane part (297 genes), catalytic activity (654 genes), binding (561genes), and etc. The analysis of the genes based on the KEGG annotation identified a total of 1046 unigenes allocated into six primary KEGG categories including 35 subcategories (Figure. S1 in Additional files). The top 5 categories of genes were: carbohydrate 
metabolism, amino acid metabolism, membrane transport, translation, and metabolism of cofactors and vitamins, respectively. The top 10 enriched pathways included ABC transporters (58 genes), Amino sugar and nucleotide sugar metabolism (27 genes), Starch and sucrose metabolism (26 genes), Glycolysis /

Gluconeogenesis (24 genes), Purine metabolism (40 genes), Pyrimidine metabolism (37 genes), Peptidoglycan biosynthesis, Aminoacyl-tRNA biosynthesis (28 genes), Ribosome (52 genes), and Quorum sensing (26 genes). The analysis based on the Clusters of Orthologous Groups (COGs) showed that 1785

unigenes were allocated to four primary COG categories containing 20 COG functional clusters. The top 5 annotated genes corresponding to the KEGG pathways were Replication recombination and repair (155 genes), Translation, ribosomal structure and biogenesis (142 genes), Amino acid transport and metabolism (126 genes), Carbohydrate transport and metabolism (110 genes), and Inorganic ion transport and metabolism (Figure. S2 in Additional files).

\section{Differential expression of global genes}

Differential gene expression analysis is commonly used to reveal the molecular mechanisms of microbial adaptation to environmental stress. As shown in Table 2, there were only 34 differentially expressed genes (DEGs, FC $\geq 2$ or $\leq 0.5$ with P-value $<0.05$ ) identified during the exponential phase between two culture conditions, of which 15 genes were upregulated, and 19 genes were downregulated more than two-fold. In addition, a total of 245 DEGs were identified at the stationary phase, of which 123 genes were significantly upregulated and 122 genes were downregulated (Table S2 in Additional files). It suggested that the addition of lactate led to differences in gene expression between the two cultures (with and without lactate supplementation) during different growth phases. 
The differentially expressed genes in culture with/without lactate supplementation during the exponential phase

\begin{tabular}{|c|c|c|c|c|c|c|c|}
\hline No. & Gene_ID & & Gene description & & TPM & $\mathrm{FC}(\mathrm{L} 1 / \mathrm{C} 1)$ & P-value \\
\hline $\mathrm{C} 1$ & & & & L1 & & & \\
\hline \multicolumn{8}{|c|}{15 upregulated genes $(F C \geq 2.0)$; all statistically significant $(P<0.05)$} \\
\hline 1 & B6259_RS06365 & atoB & acetyl-CoA C-acetyltransferase & 1224 & 5204 & 3.45 & $\begin{array}{l}7.9 \mathrm{E}- \\
39\end{array}$ \\
\hline 2 & B6259_RS06360 & crt & enoyl-CoA hydratase & 795 & 3434 & 3.46 & $\begin{array}{l}2.4 \mathrm{E}- \\
33\end{array}$ \\
\hline 3 & B6259_RS06355 & $\mathrm{hbd}$ & 3-hydroxybutyryl-CoA dehydrogenase & 1418 & 6306 & 3.49 & $\begin{array}{l}2.3 \mathrm{E}- \\
27\end{array}$ \\
\hline 4 & B6259_RS07830 & pta & phosphate acetyltransferase & 271 & 666 & 2.09 & $\begin{array}{l}4.3 \mathrm{E}- \\
24\end{array}$ \\
\hline 5 & B6259_RS00440 & - & methionine $A B C$ transporter ATP-binding protein & 51 & 504 & 5.25 & $\begin{array}{l}6.2 \mathrm{E}- \\
18\end{array}$ \\
\hline 6 & B6259_RS00450 & - & metal $A B C$ transporter substrate-binding protein & 30 & 699 & 5.69 & $\begin{array}{l}5.9 \mathrm{E}- \\
15\end{array}$ \\
\hline 7 & B6259_RS00445 & - & $A B C$ transporter permease & 27 & 446 & 5.17 & $\begin{array}{l}6.9 \mathrm{E}- \\
14\end{array}$ \\
\hline 8 & B6259_RS08190 & cysK & cysteine synthase $A$ & 390 & 7426 & 4.07 & $\begin{array}{l}6.4 \mathrm{E}- \\
10\end{array}$ \\
\hline 9 & B6259_RS08440 & - & unknown function & 1048 & 3598 & 2.33 & $\begin{array}{l}5.2 \mathrm{E}- \\
06\end{array}$ \\
\hline 10 & B6259_RS06010 & - & hypothetical protein & 21 & 89 & 2.52 & $\begin{array}{l}8.1 \mathrm{E}- \\
06\end{array}$ \\
\hline 11 & B6259_RS07140 & - & hypothetical protein & 154 & 470 & 2.17 & $\begin{array}{l}3.0 \mathrm{E}- \\
05\end{array}$ \\
\hline 12 & B6259_RS01720 & cadA & cadmium-translocating P-type ATPase & 22 & 66 & 2.16 & $\begin{array}{l}3.9 \mathrm{E}- \\
05\end{array}$ \\
\hline 13 & B6259_RS06870 & - & Hsp20/alpha crystallin family protein & 315 & 1102 & 2.21 & $\begin{array}{l}1.6 \mathrm{E}- \\
04\end{array}$ \\
\hline 14 & B6259_RS00455 & рерт & peptidase $T$ & 37 & 576 & 2.26 & $\begin{array}{l}2.0 \mathrm{E}- \\
04\end{array}$ \\
\hline 15 & B6259_RS02585 & bdh & butanol dehydrogenase & 82 & 242 & 2.04 & $\begin{array}{l}3.1 \mathrm{E}- \\
04\end{array}$ \\
\hline \multicolumn{8}{|c|}{19 downregulated genes $(F C \leq 0.5)$; all statistically significant $(P<0.05)$} \\
\hline 1 & B6259_RS08515 & - & peptide $A B C$ transporter substrate-binding protein & 98 & 53 & 0.48 & $\begin{array}{l}1.7 \mathrm{E}- \\
23\end{array}$ \\
\hline 2 & B6259_RS09280 & - & PTS glucose transporter subunit IIA & 1200 & 484 & 0.37 & $\begin{array}{l}5.5 \mathrm{E}- \\
23\end{array}$ \\
\hline 3 & B6259_RS09735 & ilvH & acetolactate synthase small subunit & 564 & 302 & 0.48 & $\begin{array}{l}9.4 \mathrm{E}- \\
19\end{array}$ \\
\hline 4 & B6259_RS06995 & - & hypothetical protein & 276 & 43 & 0.20 & $\begin{array}{l}2.7 \mathrm{E}- \\
18\end{array}$ \\
\hline 5 & B6259_RS08565 & - & hypothetical protein & 143 & 79 & 0.50 & $\begin{array}{l}2.3 \mathrm{E}- \\
13\end{array}$ \\
\hline 6 & B6259_RS07000 & - & sugar $A B C$ transporter permease & 113 & 31 & 0.30 & $\begin{array}{l}9.2 \mathrm{E}- \\
13\end{array}$ \\
\hline 7 & B6259_RS01525 & - & unknown function & 2683 & 1010 & 0.37 & $\begin{array}{l}8.4 \mathrm{E}- \\
12\end{array}$ \\
\hline 8 & B6259_RS03200 & - & unknown function & 2683 & 1010 & 0.37 & $\begin{array}{l}8.4 \mathrm{E}- \\
12\end{array}$ \\
\hline 9 & B6259_RS07010 & tag & glycosylase & 144 & 46 & 0.34 & $\begin{array}{l}9.9 \mathrm{E}- \\
11\end{array}$ \\
\hline 10 & B6259_RS07005 & - & carbohydrate $A B C$ transporter permease & 90 & 33 & 0.37 & $\begin{array}{l}1.1 \mathrm{E}- \\
09\end{array}$ \\
\hline 11 & B6259_RS01865 & - & DUF2520 domain-containing protein & 260 & 85 & 0.36 & $\begin{array}{l}6.7 \mathrm{E}- \\
09\end{array}$ \\
\hline
\end{tabular}




\begin{tabular}{|c|c|c|c|c|c|c|c|}
\hline 12 & B6259_RS01880 & panD & aspartate 1-decarboxylase & 444 & 156 & 0.37 & $\begin{array}{l}9.5 \mathrm{E}- \\
09\end{array}$ \\
\hline 13 & B6259_RS01870 & panB & $\begin{array}{l}\text { 3-methyl-2-oxobutanoate } \\
\text { hydroxymethyltransferase }\end{array}$ & 314 & 105 & 0.37 & $\begin{array}{l}1.1 \mathrm{E}- \\
08\end{array}$ \\
\hline 14 & B6259_RS01875 & panc & pantoate-beta-alanine ligase & 350 & 115 & 0.37 & $\begin{array}{l}1.2 \mathrm{E}- \\
08\end{array}$ \\
\hline 15 & B6259_RS01760 & - & hypothetical protein & 820 & 369 & 0.44 & $\begin{array}{l}8.9 \mathrm{E}- \\
08\end{array}$ \\
\hline 16 & B6259_RS02315 & - & $\begin{array}{l}\text { basic amino acid } A B C \text { transporter substrate- } \\
\text { binding protein }\end{array}$ & 147 & 79 & 0.50 & $\begin{array}{l}1.8 \mathrm{E}- \\
07\end{array}$ \\
\hline 17 & B6259_RS00100 & fruk & 1-phosphofructokinase & 1256 & 276 & 0.35 & $\begin{array}{l}1.7 \mathrm{E}- \\
06\end{array}$ \\
\hline 18 & B6259_RS00095 & - & PTS fructose transporter subunit IIC & 1273 & 372 & 0.37 & $\begin{array}{l}1.8 \mathrm{E}- \\
06\end{array}$ \\
\hline 19 & B6259_RS00105 & - & DeoR/GlpR transcriptional regulator & 1304 & 278 & 0.36 & $\begin{array}{l}3.6 \mathrm{E}- \\
06\end{array}$ \\
\hline
\end{tabular}

L1: lactate-supplemented cells at exponential phase

C1: no-lactate-supplemented cells (controls) at exponential phase

The COG distribution of the DEGs at both the exponential phase and the stationary phase was illustrated in Figure 4. It revealed the potential genes related to the pathways and bioprocesses for the utilization of lactate for CA production. At the exponential phase, predominant number of DEGs belong to the 'inorganic ion transport and metabolism, [P]' group and the 'carbohydrate transport and metabolism, [G]' group. While at stationary phase, most upregulated genes belong to the 'carbohydrate transport and metabolism, [G]' group, which play important roles for the degradation and utilization of carbohydrate substrates [20,21]. It was worth noting that a large number of DEGs (for both upregulated and downregulated ones) fall into the 'function unknown, [S]' group.), meaning that their functions are unknown. This may be because CPB6 belongs to a novel species or clade (Clostridium cluster IV) of the family Ruminococcaceae, sharing low $16 \mathrm{~S}$ rRNA sequence similarity (<92.6\%) with the other organisms in GenBank and RDP [15, 17].

Cluster analysis of the DEGs between the culture with lactate supplementation and the control was showed in Figure 5 . The results indicated that the gene expression of the triplicate ( $a, b$ and $c$ ) of each sample demonstrated very similar expression patterns (Figure 5). The two cultures (with or without lactate supplementation) were cluster together at the exponential phase, indicating the presence of a

small amount of DEGs caused by the addition of lactate at this phase. However, the distinct difference of gene expression was observed between the two cultures at the stationary phase, implying that supplemented lactate induces greater metabolic shift at this phase. These DEGs were described in detail in later section.

\section{Expression of glycolysis genes}

An overview of the metabolic pathway in strain CPB6 and the expression levels of genes involved in key metabolic processes with their fold change (FC) were shown in Figure 6 and Table 3. Generally, in clostridia, glucose is converted into pyruvate via glycolysis, and the produced pyruvate is further converted into acetyl-CoA for the production of acetate and butyrate at acidogenic phase [22-24]. In the present study, the expression of genes for glycolysis was detected in the CPB6 transcriptome, which reinforced its genome annotation [17]. Most glycolytic genes were expressed at a relatively high level (TPM>150) between the culture with lactate supplementation and the control, but there was no significant difference between them at the exponential phase. Three glycolytic genes exhibited different expression patterns at the stationary phase. Genes encoding glucose-1-phosphate adenylyltransferase (GlgC, B6259_RS09035) and 1, 4alpha-glucan branching enzyme (GlgB, B6259_RS09040) were upregulated by 4.58 and 3.42-fold in the culture with lactate supplementation than in the control, respectively. Gene encoding phosphofructokinase (PFK, B6259_RS06095) was significantly downregulated. Generally, the addition of lactate has little impact on the expression of glycolytic genes. Notably, the expression of the gene encoding glucokinase (GK) was not detected in the transcriptome under either condition. GK is a rate-limiting enzyme in glycolysis mediating glucose-induced insulin release by regulating intracellular ATP production. The reason for the absence of GK expression warrants further investigation. 
Table 3

The differentially expressed genes within the important metabolic pathways in culture with/without lactate supplementation

\begin{tabular}{|c|c|c|c|c|c|c|c|}
\hline \multirow{2}{*}{$\begin{array}{l}\text { Functional description } \\
12 \mathrm{~h}\end{array}$} & \multicolumn{2}{|c|}{ Gene_ID } & \multicolumn{2}{|c|}{$\begin{array}{l}\text { TPM of genes from culture with } \\
\text { lactate supplementationa }\end{array}$} & \multirow{2}{*}{$\begin{array}{l}\text { TPM of genes } \\
\text { from the Controla } \\
12 \mathrm{~h}\end{array}$} & \multicolumn{2}{|c|}{$\begin{array}{l}\text { RNA relative fold } \\
\text { change } \\
\text { (Treatment/Control) }\end{array}$} \\
\hline & $18 \mathrm{~h}$ & & $12 \mathrm{~h}$ & $18 \mathrm{~h}$ & & $18 \mathrm{~h}$ & \\
\hline \multicolumn{8}{|l|}{ Glycolysis } \\
\hline $\begin{array}{l}\text { PTS-Glc-EIIA, PTS glucose } \\
\text { transporter subunit IIA }\end{array}$ & B6259_RS09280 & 484 & 260 & 1200 & 517 & $0.37 b$ & 0.62 \\
\hline $\begin{array}{l}\text { GlgC, glucose-1-phosphate } \\
\text { adenylyltransferase }\end{array}$ & B6259_RS09035 & 153 & 1323 & 236 & 241 & 0.57 & $4.58 \mathrm{c}$ \\
\hline $\begin{array}{l}\text { GlgB, 1,4-alpha-glucan } \\
\text { branching enzyme }\end{array}$ & B6259_RS09040 & 194 & 745 & 236 & 201 & 0.72 & $3.42 \mathrm{c}$ \\
\hline $\begin{array}{l}\text { sugar phosphate } \\
\text { isomerase/epimerase }\end{array}$ & B6259_RS06500 & 181 & 175 & 150 & 233 & 1.05 & 0.88 \\
\hline PGM, phosphoglucomutase & B6259_RS09200 & 95 & 189 & 127 & 113 & 0.66 & 1.80 \\
\hline $\begin{array}{l}\text { GPI, glucose-6-phosphate } \\
\text { isomerase }\end{array}$ & B6259_RS04825 & 2015 & 1789 & 1833 & 1818 & 0.96 & 1.12 \\
\hline PFK, phosphofructokinase & B6259_RS06095 & 426 & 97 & 580 & 516 & 0.66 & $0.23 \mathrm{~b}$ \\
\hline $\begin{array}{l}\text { ALDO, fructose-bisphosphate } \\
\text { aldolase }\end{array}$ & B6259_RS00415 & 749 & 402 & 800 & 891 & 0.83 & 0.57 \\
\hline TPI, triose-phosphate isomerase & B6259_RS09105 & 224 & 229 & 315 & 493 & 0.65 & 0.58 \\
\hline $\begin{array}{l}\text { GapA, glyceraldehyde } \\
\text { phosphate dehydrogenase }\end{array}$ & B6259_RS09050 & 5322 & 4284 & 4790 & 7732 & 0.98 & 0.70 \\
\hline PGK, phosphoglycerate kinase & B6259_RS09100 & 523 & 524 & 705 & 1029 & 0.67 & 0.65 \\
\hline $\begin{array}{l}\text { gpml, 2,3-bisphosphoglycerate- } \\
\text { independent phosphoglycerate } \\
\text { mutase }\end{array}$ & B6259_RS09110 & 203 & 200 & 284 & 469 & 0.66 & 0.55 \\
\hline $\begin{array}{l}\text { ENO, phosphopyruvate } \\
\text { hydratase }\end{array}$ & B6259_RS04810 & 41 & 65 & 30 & 52 & 1.14 & 1.46 \\
\hline PK, pyruvate kinase & B6259_RS02335 & 254 & 102 & 293 & 228 & 0.77 & 1.46 \\
\hline \multicolumn{8}{|l|}{ Central pyruvate metabolism } \\
\hline $\begin{array}{l}\text { PpdK, pyruvate phosphate } \\
\text { dikinase }\end{array}$ & B6259_RS00120 & 1301 & 823 & 1163 & 1535 & 0.99 & 0.69 \\
\hline $\begin{array}{l}\text { Pfor, pyruvate: ferredoxin } \\
\text { (flavodoxin) oxidoreductase }\end{array}$ & B6259_RS09135 & 4329 & 4382 & 2044 & 1225 & 1.83 & $3.26 \mathrm{c}$ \\
\hline $\begin{array}{l}\text { PCK, phosphoenolpyruvate } \\
\text { carboxykinase }\end{array}$ & B6259_RS09255 & 368 & 159 & 554 & 1031 & 0.62 & $0.23 \mathrm{~b}$ \\
\hline $\begin{array}{l}\text { PflD, formate C- } \\
\text { acetyltransferase }\end{array}$ & B6259_RS09900 & 98 & 188 & 107 & 471 & 0.83 & 0.54 \\
\hline ADH, alcohol dehydrogenase & B6259_RS03100 & 200 & 116 & 163 & 159 & 1.07 & 0.84 \\
\hline \multicolumn{8}{|l|}{ Incomplete TCA cycle } \\
\hline $\begin{array}{l}\text { CS, citrate synthase, citrate } \\
\text { lyase }\end{array}$ & B6259_RS03360 & 936 & 187 & 543 & 642 & 1.42 & $0.39 \mathrm{~b}$ \\
\hline ACO, aconitate hydratase & B6259_RS05795 & 227 & 162 & 153 & 201 & 1.27 & 0.94 \\
\hline IDH, isocitrate dehydrogenase & B6259_RS05805 & 237 & 232 & 197 & 291 & 1.04 & 0.93 \\
\hline FUM, fumarate hydratase & B6259_RS07270 & 310 & 186 & 260 & 437 & 1.04 & $0.49 \mathrm{~b}$ \\
\hline $\begin{array}{l}\text { PCK, phosphoenolpyruvate } \\
\text { carboxykinase }\end{array}$ & B6259_RS09255 & 368 & 159 & 554 & 1031 & 0.62 & $0.23 \mathrm{~b}$ \\
\hline \multicolumn{8}{|l|}{ Hydrogen production } \\
\hline $\begin{array}{l}\text { HydE, [FeFe] hydrogenase } \mathrm{H} \text { - } \\
\text { cluster }\end{array}$ & B6259_RS02550 & 113 & 73 & 174 & 44 & 1.44 & $2.24 \mathrm{c}$ \\
\hline $\begin{array}{l}\text { HydF, [FeFe] hydrogenase } \mathrm{H}- \\
\text { cluster }\end{array}$ & B6259_RS09690 & 67 & 40 & 50 & 24 & 1.43 & 1.17 \\
\hline
\end{tabular}




\begin{tabular}{|c|c|c|c|c|c|c|c|c|}
\hline D-Idh, D-lactate dehydrogenase & B6259_RS06770 & 76 & 88 & 58 & 108 & & 1.14 & 0.95 \\
\hline L-Idh, L-lactate dehydrogenase & B6259_RS09845 & 79 & 111 & 119 & 295 & & 0.59 & $0.44 \mathrm{~b}$ \\
\hline \multicolumn{9}{|l|}{ Acetate fermentation pathway } \\
\hline $\begin{array}{l}\text { PTA, phosphate } \\
\text { acetyltransferase }\end{array}$ & B6259_RS07830 & 666 & 697 & 271 & 321 & $\begin{array}{l}2.09 \\
c\end{array}$ & $2.23 \mathrm{c}$ & \\
\hline ACK, acetate kinase & B6259_RS03430 & 290 & 297 & 288 & 233 & 0.88 & 1.41 & \\
\hline \multicolumn{9}{|l|}{ The reverse $\beta$-oxidation pathway } \\
\hline $\begin{array}{l}\text { AtoB, acetyl-CoA C- } \\
\text { acetyltransferase }\end{array}$ & B6259_RS06365 & 5204 & 9909 & 1224 & 1077 & $\begin{array}{l}3.45 \\
c\end{array}$ & $6.31 c$ & \\
\hline $\begin{array}{l}\text { HBD, 3-hydroxybutyryl-CoA } \\
\text { dehydrogenase }\end{array}$ & B6259_RS06355 & 6306 & 13975 & 1418 & 1022 & $\begin{array}{l}3.49 \\
c\end{array}$ & $8.59 \mathrm{c}$ & \\
\hline CRT, enoyl-CoA hydratase & B6259_RS06360 & 3434 & 7348 & 795 & 647 & $\begin{array}{l}3.46 \\
c\end{array}$ & $7.34 \mathrm{c}$ & \\
\hline $\begin{array}{l}\text { BCD1, butyryl-CoA } \\
\text { dehydrogenase }\end{array}$ & B6259_RS01790 & 3278 & 3104 & 3787 & 3014 & 0.76 & 1.19 & \\
\hline $\begin{array}{l}\text { BCD2, butyryl-CoA } \\
\text { dehydrogenase }\end{array}$ & B6259_RS02600 & 42 & 313 & 41 & 66 & 0.90 & $4.49 \mathrm{c}$ & \\
\hline $\begin{array}{l}\text { CAT, butyryl-CoA: acetate CoA- } \\
\text { transferase }\end{array}$ & B6259_RS06345 & 521 & 1497 & 283 & 330 & 1.55 & $4.01 \mathrm{c}$ & \\
\hline \multicolumn{9}{|l|}{ Fructose fermentation pathway } \\
\hline PPF, 1-phosphofructokinase & B6259_RS00100 & 276 & 2174 & 1256 & 239 & 0.35 & 7.33 & \\
\hline \multicolumn{9}{|l|}{ Starch and sucrose metabolism } \\
\hline PYG, glycogen phosphorylase & B6259_RS00300 & 90 & 163 & 121 & 103 & 0.66 & 1.71 & \\
\hline $\begin{array}{l}\text { MalQ, 4-alpha- } \\
\text { glucanotransferase }\end{array}$ & B6259_RS07805 & 53 & 270 & 55 & 61 & 0.85 & 4.34 & \\
\hline PGM, Phosphoglucomutase & B6259_RS09200 & 95 & 189 & 127 & 113 & 0.66 & 1.80 & \\
\hline \multicolumn{9}{|l|}{ Energy conservation } \\
\hline $\begin{array}{l}\text { energy-coupling factor } \\
\text { transporter ATPase }\end{array}$ & B6259_RS02790 & 141 & 104 & 117 & 159 & 1.04 & 0.76 & \\
\hline $\begin{array}{l}\text { electron transport complex } \\
\text { protein RnfA }\end{array}$ & B6259_RS06245 & 230 & 162 & 357 & 362 & 0.58 & 0.52 & \\
\hline \multicolumn{9}{|l|}{ Sporulation } \\
\hline stage 0 sporulation protein & B6259_RS00205 & 379 & 279 & 233 & 252 & 0.97 & 0.82 & \\
\hline stage II sporulation protein D & B6259_RS09065 & 98 & 59 & 96 & 53 & 0.97 & 1.29 & \\
\hline stage III sporulation protein AD & B6259_RS03910 & 126 & 54 & 87 & 26 & 1.67 & 1.27 & \\
\hline stage IV sporulation protein A & B6259_RS04975 & 65 & 30 & 58 & 16 & 1.42 & 1.58 & \\
\hline stage $V$ sporulation protein $A C$ & B6259_RS09190 & 89 & 46 & 77 & 40 & 0.99 & 1.42 & \\
\hline stage $V$ sporulation protein $A D$ & B6259_RS09195 & 69 & 41 & 66 & 34 & 1.05 & 1.57 & \\
\hline stage $\mathrm{V}$ sporulation protein $\mathrm{AE}$ & B6259_RS00500 & 292 & 226 & 200 & 167 & 1.15 & 1.02 & \\
\hline $\begin{array}{l}\text { sporulation transcription factor } \\
\text { Spo0A }\end{array}$ & B6259_RS05505 & 127 & 115 & 83 & 106 & 0.94 & 0.94 & \\
\hline $\begin{array}{l}\text { sporulation transcriptional } \\
\text { regulator SpollID }\end{array}$ & B6259_RS01550 & 213 & 188 & 140 & 207 & 0.79 & 1.01 & \\
\hline sporulation protein YtfJ & B6259_RS04885 & 291 & 183 & 145 & 159 & 1.00 & 0.65 & \\
\hline \multicolumn{9}{|l|}{ Transporter genes } \\
\hline $\mathrm{ABC}$ transporter permease & B6259_RS00445 & 446 & 274 & 27 & 235 & $\begin{array}{l}5.17 \\
c\end{array}$ & 1.27 & \\
\hline metal $A B C$ transporter & B6259_RS00450 & 699 & 628 & 30 & 457 & $\begin{array}{l}5.69 \\
c\end{array}$ & 1.52 & \\
\hline$A B C$ transporter permease & B6259_RS02670 & 296 & 130 & 441 & 387 & 0.60 & $0.40 \mathrm{~b}$ & \\
\hline $\mathrm{ABC}$ transporter permease & B6259_RS02665 & 180 & 96 & 258 & 231 & 0.62 & $0.48 \mathrm{~b}$ & \\
\hline
\end{tabular}




\begin{tabular}{|c|c|c|c|c|c|c|c|}
\hline $\begin{array}{l}\text { carbohydrate } A B C \text { transporter } \\
\text { permease }\end{array}$ & B6259_RS07005 & 33 & 124 & 90 & 41 & $\begin{array}{l}0.37 \\
b\end{array}$ & $3.51 \mathrm{c}$ \\
\hline $\begin{array}{l}\text { carbohydrate } A B C \text { transporter } \\
\text { permease }\end{array}$ & B6259_RS07905 & 71 & 744 & 71 & 40 & 0.90 & $12.71 \mathrm{c}$ \\
\hline $\begin{array}{l}\text { carbohydrate } A B C \text { transporter } \\
\text { permease }\end{array}$ & B6259_RS07810 & 39 & 229 & 40 & 45 & 0.85 & $5.48 \mathrm{c}$ \\
\hline $\begin{array}{l}\text { carbohydrate } A B C \text { transporter } \\
\text { permease }\end{array}$ & B6259_RS02030 & 26 & 71 & 16 & 39 & 1.35 & $2.14 \mathrm{c}$ \\
\hline $\begin{array}{l}\text { sugar } A B C \text { transporter } \\
\text { permease }\end{array}$ & B6259_RS07910 & 82 & 1175 & 88 & 50 & 0.86 & $14.74 \mathrm{c}$ \\
\hline $\begin{array}{l}\text { sugar } A B C \text { transporter } \\
\text { permease }\end{array}$ & B6259_RS03335 & 39 & 401 & 26 & 61 & 1.30 & $5.61 \mathrm{c}$ \\
\hline $\begin{array}{l}\text { sugar } A B C \text { transporter } \\
\text { permease }\end{array}$ & B6259_RS07815 & 36 & 197 & 37 & 49 & 0.85 & $4.34 \mathrm{c}$ \\
\hline $\begin{array}{l}\text { sugar } A B C \text { transporter } \\
\text { permease }\end{array}$ & B6259_RS07000 & 31 & 135 & 113 & 38 & $\begin{array}{l}0.30 \\
b\end{array}$ & $3.48 \mathrm{c}$ \\
\hline iron $A B C$ transporter permease & B6259_RS00320 & 53 & 1278 & 77 & 89 & 0.62 & $10.05 \mathrm{c}$ \\
\hline $\begin{array}{l}\text { ABC transporter ATP-binding } \\
\text { protein }\end{array}$ & B6259_RS00440 & 504 & 277 & 51 & 239 & $\begin{array}{l}5.25 \\
c\end{array}$ & 1.39 \\
\hline $\begin{array}{l}\text { ABC transporter ATP-binding } \\
\text { protein }\end{array}$ & B6259_RS00325 & 60 & 2032 & 94 & 100 & 0.58 & $11.14 \mathrm{c}$ \\
\hline $\begin{array}{l}\text { ABC transporter ATP-binding } \\
\text { protein }\end{array}$ & B6259_RS08900 & 153 & 682 & 233 & 214 & 0.58 & 3.13 \\
\hline $\begin{array}{l}\text { ABC transporter ATP-binding } \\
\text { protein }\end{array}$ & B6259_RS07940 & 190 & 40 & 259 & 94 & 0.66 & 0.42 \\
\hline $\begin{array}{l}\text { carbohydrate } A B C \text { transporter } \\
\text { substrate-binding protein }\end{array}$ & B6259_RS07915 & 216 & 3434 & 203 & 103 & 0.93 & 14.51 \\
\hline $\begin{array}{l}\text { maltose } A B C \text { transporter } \\
\text { substrate-binding protein }\end{array}$ & B6259_RS03345 & 30 & 501 & 22 & 37 & 1.15 & 7.65 \\
\hline $\begin{array}{l}\text { ABC transporter substrate- } \\
\text { binding protein }\end{array}$ & B6259_RS07820 & 372 & 1913 & 451 & 344 & 0.73 & 4.63 \\
\hline $\begin{array}{l}\text { sugar } A B C \text { transporter } \\
\text { substrate-binding protein }\end{array}$ & B6259_RS02005 & 30 & 93 & 29 & 48 & 0.92 & 2.29 \\
\hline $\begin{array}{l}\text { peptide } A B C \text { transporter } \\
\text { substrate-binding protein }\end{array}$ & B6259_RS08515 & 53 & 78 & 98 & 369 & 0.48 & 0.28 \\
\hline $\begin{array}{l}\text { peptide } A B C \text { transporter } \\
\text { substrate-binding protein }\end{array}$ & B6259_RS02685 & 1385 & 819 & 1442 & 2222 & 0.85 & 0.50 \\
\hline $\begin{array}{l}\text { ABC transporter ATP-binding } \\
\text { protein }\end{array}$ & B6259_RS02660 & 238 & 119 & 369 & 320 & 0.58 & 0.45 \\
\hline $\begin{array}{l}\text { ABC transporter ATP-binding } \\
\text { protein }\end{array}$ & B6259_RS07940 & 190 & 58 & 259 & 166 & 0.66 & 0.42 \\
\hline $\begin{array}{l}\text { PTS fructose transporter } \\
\text { subunit IIC }\end{array}$ & B6259_RS00095 & 372 & 2117 & 1273 & 485 & 0.37 & 3.87 \\
\hline $\begin{array}{l}\text { PTS glucose transporter subunit } \\
\text { IIA }\end{array}$ & B6259_RS09280 & 484 & 260 & 1200 & 517 & 0.37 & 0.62 \\
\hline $\begin{array}{l}\text { PTS } \beta \text {-glucoside transporter } \\
\text { subunit IIABC }\end{array}$ & B6259_RS01415 & 81 & 760 & 134 & 141 & 0.54 & 4.70 \\
\hline $\begin{array}{l}\text { PTS mannitol transporter } \\
\text { subunit IICBA }\end{array}$ & B6259_RS00370 & 29 & 89 & 19 & 44 & 1.26 & 2.34 \\
\hline ferrous iron transport protein $B$ & B6259_RS03880 & 471 & 389 & 531 & 150 & 0.81 & 2.72 \\
\hline
\end{tabular}

a, Data presented as mean of independent triplicates

b, Significantly upregulated $(F C \geq 2.0, p<0.05)$

c, Significantly downregulated $(\mathrm{FC} \leq 0.5, \mathrm{p}<0.05)$

\section{Expression of butyrate- and CA-producing genes}

The bioproduction of CA is a well-known chain elongation process from acetate (C2) to caproate (C6) via the reverse $\beta$-oxidation pathway, in which an acetyl$\mathrm{CoA}$ (from ethanol) unit is combined with another acetyl-CoA (from acetate), and consequently C2 is elongated to C4, and further C4 is elongated to C6 [4]. Thus, acetyl-CoA is a key intermediate of flux distribution for the chain elongation. The conversion of pyruvate into acetyl-CoA is mainly catalyzed by the 
pyruvate: ferredoxin (flavodoxin) oxidoreductase (Pfor) that is a flavodoxin- and NADPH-dependent enzyme [6, 25]. Here, the Pfor gene (B6259_RS09135) maintained at very high expression level $(T P M>4000)$ in the culture with lactate

supplementation (Table 3), which were upregulated by 1.83- and 3.26-fold than that in the control in the exponential and stationary phase, respectively (Figure 6). High-level expression of the Pfor gene would result in increased acetyl-CoA, which provides the high amount of acetyl-CoA for chain elongation from acetate to butyrate and CA.

Key enzymes involved in the butyrate formation include acetyl-CoA C-acetyltransferase (AtoB), 3-hydroxybutyryl-CoA dehydrogenase (HBD), enoyl-CoA hydratase (CRT), NAD-dependent butyryl-CoA dehydrogenase (BCD), and butyryl-CoA: acetate CoA transferase (CAT) [6, 17]. Here, genes encoding AtoB (B6259_RS06365), CRT (B6259_RS06360) and HBD (B6259_RS06355) were identified from the transcriptomes of strain CPB6, whose expression levels maintained at very high levels (TPM>3000) in the culture with lactate supplementation throughout the exponential and stationary phases, and were upregulated by 3.5-8.6 folds compared to the control. It suggested that the high-level expression of the three genes can be induced by supplemented lactate. In addition, two BCD genes (B6259_RS01790 and_RS02600) responsible for the conversion of crotonyl-CoA to butyryl-CoA showed different expression profiles. B6259_RS01790 was expressed at a very high level $(T P M>3000)$ throughout the fermentation phases, but it showed no change in expression in the two cultures. B6259_RS02600 was expressed at relative low level at the exponential phase, but its expression was induced to high levels in the culture with lactate supplementation at the stationary phase, which was $>4.4$-fold higher than that in the control. More research is needed to determine which $B C D$ gene plays the key role in acidogenesis in the CPB6. A CAT gene (B6259_RS06345) was detected in the CPB6 transcriptome, and its expression was markedly upregulated by 4-fold in the culture with lactate supplementation than that in the control in the stationary phase, and kept at very high expression levels. CAT is key enzyme responsible for catalysing the last step of the butyrate formation [25]. High-level expression of CAT gene should theoretically result in a high concentration of butyric acid in the culture with lactate supplementation. Nevertheless, significant accumulation of CA instead of butyric acid was observed in culture with lactate supplementation, suggesting that the CAT is likely more intent to transforming caproy-CoA to caproate instead of converting butyryl-CoA to butyrate. Up to now, little is known about the key functional genes responsible for CA synthesis from butyryl-CoA. Genes involved in butyrate synthesis via the reverse $\beta$ oxidation (e.g., AtoB, CRT, HBD, BCD and CAT) are assumed to have the function in the caproy-CoA and CA formation [6]. However, Clostridium sp. BPY5 and C. tyrobutyricum, which contains these genes, only produce

butyric acid instead of CA [25, 26], while $C$. kluyveri and Ruminococcaceae bacterium CPB6, which contain these genes, can further elongate butyric acid to CA $[6,16]$. It suggested that there may be differences in structure and function between these genes from different organisms. Therefore, the further study needs to be performed to explore the functions of these genes in strain CPB6.

Lactate is a major endproduct of glycolysis in the absence of oxygen [27]. Its formation or conversion requires lactate dehydrogenase (LDH) with the regeneration of NADH to NAD+. There are two LDH genes in the CPB6 genome [17], encoding L-lactate dehydrogenase (L-LDH) and D-lactate dehydrogenase (D-LDH), respectively. In this study, the expression of LDH genes (L-LDH, B6259_RS09845; D-LDH, B6259_RS06770) were also detected in the transcripts of strain CPB6. However, the two genes showed relatively low expression levels in both the culture with lactate supplementation and the control, except that slightly higher expression level was observed in the control at the stationary phase (Table 3). LDH catalyzes the reaction converts pyruvate to lactate or the reverse reaction that converts lactate to pyruvate [28]. This conversion is essential in hypoxic and anaerobic conditions when ATP production by oxidative phosphorylation is disrupted. The recent study showed that lactate can be transformed into CA in either mixed microbiome [2, 13, 14], or in the pure culture where the conversion of lactate to acetyl-CoA coupling with the reverse $\beta$-oxidation is speculated to result into chain elongation [15]. Interestingly, the lactate supplementation in this study did not lead to increased expression levels of LDHs in either exponential or stationary phases, indicating that the expression of LDHs might be uncoupled from the utilization of lactate. It warrants further investigation concerning the function of LDH in the conversion of lactate to CA in the CPB6 strain.

The gene encoding phosphate acetyltransferase (PTA, B6259_RS07830), one important enzyme involved in acetate formation, was remarkably upregulated in the culture with lactate supplementation than in the control. However, the expression of acetate kinase (ACK, B6259_RS03430) showed no change in response to the addition of lactate. By including the production of $\mathrm{H} 2$ and $\mathrm{CO} 2$ into the loop, it could provide a whole picture for carbon balance for the substrate utilization and cell biomass production. Unfortunately, the production of $\mathrm{H} 2$ and $\mathrm{CO} 2$ was not monitored in this study. In the future studies, this should be taken into consideration for improvement.

\section{Expression of putative $\mathrm{ABC}$ transporter and sporulation genes}

Strain CPB6, affiliated with Clostridium cluster IV of the family Ruminococcaceae in the order of

Clostridiales, is a spore-forming, obligate anaerobic bacterium that can produce CA from lactate (Zhu et al. 2017). As shown in Table 3, sporulation genes showed similar expression patterns in both groups, e.g., spo0, spollID, spoV, spoYtfJ, were induced to high expression under both conditions (with or without lactate supplementation) at the exponential and stationary phases, while spolID, spollIAD, spoIVA, spoVAC, spoVAD spoVAE were expressed at low or moderate levels. Some bacteria, such as bacilli and clostridia, develop into highly resistant spores to protect their genome from certain doom when living conditions become intolerable [29]. It ensures bacterial survival under adverse environmental conditions. Sporulation in Clostridium spp. is ordinarily not triggered by starvation but by cessation of growth in the presence of excess carbon source or exposure to oxygen [30]. The two most critical factors involved in the shift to solventogenesis, a decrease in external $\mathrm{pH}$ and accumulation of acidic fermentation products, are generally assumed to be associated with the initiation of sporulation in Clostridium spp., to some extent [31]. But recent studies showed that the sporulation events were uncoupled from the induction of solventogenesis in $C$. beijerinckii [22]. In this study, the sporulation genes showed no significant difference between the culture with lactate supplementation and the control, indicating that the sporulation events are not associated with the production of CA in the CPB6 until the stationary phase. 
In the transcriptome of strain CPB6, most genes encoding ATP-binding cassette (ABC) transporters and substrate-bind proteins (SBP) maintained at low expression levels in the control, but were induced to relatively high expression levels (particularly upregulated by 2-14 folds at the stationary phase) in the culture with lactate supplementation. ABC transporters are ubiquitous membrane proteins that couple the transport of diverse substrates across cellular membranes to the hydrolysis of ATP [32]. ABC transporters are generally divided into importers and exporters on the basis of the polarity of solute movement. $A B C$ importers are found mostly in bacteria and are crucial in mediating the uptake of solutes including sugar, metal ions and vitamins [33]. In the present study, most genes for $A B C$ transporter and substrate-binding protein (SBP) were no significant change in the two cultures in the exponential phase, except two ABC transporter genes (B6259_RS00445, B6259_RS00450), and one SBP gene (B6259_RS00440) which were upregulated by more than 2-fold in the culture with lactate supplementation than in the control. This indicated that the three genes might be related to the intake and use of lactic acid. In addition, nine $A B C$ transporter genes and six SBP genes were markedly upregulated at the stationary phase. Specially, B6259_RS07905,_RS07910,_RS00320, _RS00325 and

B6259_RS07915 were increased over 10-fold in the culture with lactate supplementation than in the control, demonstrating that these genes are associated with the extrusion of CA from the cell and the maintenance of osmotic homeostasis in cytoplasm [34].

In addition, two phosphotransferase system (PTS) transporter genes (B6259_RS01415 and B6259_RS00370) and one ferrous iron transporter gene (B6259_RS03880) were upregulated by 2- to 4-fold in the culture with lactate supplementation than in the control. PTS is a multiple-component carbohydrate uptake system that drives specific saccharides across the bacterial inner membrane while simultaneously catalyzing sugar phosphorylation [35]. Five distinct subfamilies of proteins related to PTS have been identified within the glucose superfamily: the lactose family, the glucose family, the $\beta$-glucoside family, the mannitol family, and the fructose family [36]. In this study, four PTS transporter genes were detected in the transcriptome of strain CPB6, including PTS fructose transporter subunit IIC (B6259_RS00095), PTS glucose transporter subunit IIA (B6259_RS09280), PTS $\beta$-glucoside transporter subunit IIABC (B6259_RS01415), and PTS mannitol transporter subunit IICBA (B6259_RS00370). Genes encoding PTS fructose and glucose transporters were highly expressed under both conditions, but the two genes were significantly downregulated at the exponential phase in the culture with lactate supplementation than in the control, indicating that PTS transporter-mediated sugar transport in membrane vesicles in CPB6 is inhibited by the lactate supplementation. However, at the stationary phase, genes encoding PTS fructose, $\beta$-glucoside and mannitol transporters were all strikingly upregulated. This is probably because PTS transporter-mediated sugar transport in membrane vesicles decreased with the exhaustion of glucose in the control. While in the culture with lactate supplementation, the utilization of glucose was slightly slowed down, and thus PTS transporter was upregulated to regain sugar transport as soon as lactate is depleted.

\section{Conclusions}

This study showed that lactate supplementation induced earlier CA production, higher CA titer and productivity, but had little impact on cell growth, suggesting that the supplemented lactate is more involved in secondary metabolism (e.g., the production of CA) than the carbon assimilation. The gene transcriptional profiles based on RNA-Seq demonstrated that supplemented lactate promoted CA production by altering the expression patterns of genes involved in crucial metabolic pathways. Specifically, the Pfor gene involved in central pyruvate metabolism, 5 genes (AtoB, HBD, CRT, BCD and CAT) involved in the reverse $\beta$ oxidation pathway, 11 genes encoding ABC transporter, 6 SBP genes, and 4 PTS transporter genes showed sharp upregulation in response to the addition of lactate. The findings presented herein provide unique insights into the metabolic effects of lactate on CA production at the gene regulation level.

\section{Materials And Methods}

\section{Microorganisms, media and fermentation experiment}

Ruminococcaceae bacterium CPB6 (GDMCC No.60133) was routinely cultured at 37 oC anaerobically in a modified tryptone-glucose-yeast extract (mTGY) medium containing the following compounds ( $\mathrm{g} \mathrm{L-1,} \mathrm{pH} 6.0$ ): tryptone, 5.0; glucose, 2.0; yeast extract, 5.0; sodium acetate, 3.5; $\mathrm{K} 2 \mathrm{HPO} 4 \cdot 3 \mathrm{H} 2 \mathrm{O}, 0.41 ; \mathrm{KH} 2 \mathrm{PO} 4$, 0.23; NH4Cl, 0.25; MgSO4.7H2O, 0.20; NaHCO3, 2.5; L-cysteine, 0.25; Na2S.9H2O, 0.25; resazurin, 0.0005; and $1 \mathrm{ml}$ of trace element solution SL-10 and 1ml of vitamin solution [14]. The suspension of activated strain CPB6 was inoculated with a $5 \%$ ratio into the same medium as described above and incubated for 12-15 $\mathrm{h}$ until the OD600 of the culture reached 0.8-1.0. Then the culture would be used as the seed inoculum (5\% ratio, v/v) for batch experiments. To investigate the effect of lactate on cell growth and CA production, $5 \mathrm{~g} \mathrm{~L}-1$ sodium lactate was supplemented into the modified TGY medium (mTGYL). Batch experiments were performed in $250 \mathrm{~mL}$ serum bottles containing $100 \mathrm{~mL}$ of modified mTGY or mTGYL media. The headspace of the bottle was filled with highly pure N2. Each fermentation was performed in triplicate. The fermentation was carried out at 37 oC for $24 \mathrm{~h}$ in an E500 anaerobic workstation (Gene Science, USA) under N2: CO2: H2 (volume ratio of 80:10:10) atmosphere.

Samples were taken at specific times and processed for cell concentration determination and HPLC analysis. Samples for RNA isolation were taken at the exponential and stationary phases of the cell growth.

\section{Analytical methods}

Culture growth was monitored by measuring the optical density at $600 \mathrm{~nm}$ (OD600) using a TU-1810 UV/Vis Spectrophotometer (Puxi Instrument Co. Ltd., Beijing). Lactic acid, acetic acid, butyric acid, and caproic acid were quantified using an HPLC system (Agilent 1260 Infinity, USA) equipped with a differential refraction detector (RID) and a Agilent Hi-Plex H column $(300 \times 6.5 \mathrm{~mm})$ following the procedure as previously described [16].

\section{RNA isolation, library construction, and sequencing}


In preparation for RNA isolation, $10 \mathrm{ml}$ cell culture was harvested at each time point, and centrifuged at $8,000 \times \mathrm{g}$ for $10 \mathrm{~min}$ at $4{ }^{\circ} \mathrm{C}$. Cells were then frozen in liquid nitrogen prior to storage at $-80^{\circ} \mathrm{C}$. The RNA was extracted and purified using a RNA extraction kit (DP430, Tiangen Biotech, Beijing, China) following the manufacturer's protocol. RNA quality and quantity were characterized using a NanoDrop2000 (NanoDrop Technologies, Wilmington, DE), agarose gel electrophoresis (RNA integrity detection) and Agilent 2100 (RIN value measurement). Only the RNA samples with high-quality ( $\geq 5 \mu \mathrm{g} ; \geq 200 \mathrm{ng} / \mu \mathrm{L}$; OD260/280=1.8 2.2) were used for the cDNA library construction and sequencing. Before library construction, rRNAs were removed with the Ribo-Zero rRNA Removal Kit (Epicentre, San Diego, CA) following the manufacturer's protocol. The enriched mRNA was fragmented into short fragments (approximately 200 bp) randomly using metal ions. Then the first strand cDNA was synthesized using the random hexamer-primer with the mRNA fragment as the template. After synthesizing the second strand cDNA using DNA polymerase I and RNase $\mathrm{H}$, double-stranded cDNA was further end repaired, A-tailed, and indexed adapters ligated. The final cDNA library was constructed using the mRNA-Seq library construction kit (Illumina Inc., San Diego, CA), and then sequenced by Illumina platform (Illumina Inc., San Diego, CA).

\section{RNA-Seq data analysis}

High quality reads in each sample were aligned to the CPB6 genome using Bowtie2, and those that did not align uniquely to the genome were discarded using the default quality parameters. Each base was assigned a value based on the number of mapped sequence coverage. Gene expression levels were defined using the number of transcripts per million (TPM), which is proportional to the quantity of cDNA fragments derived from the gene transcripts. The quantitative gene expression values between samples were identified by calculating the number of unambiguous tags for each gene and then normalizing this to TPM, which was calculated following the method reported by Parto et al., [37]. The gene expression results were visualized using heatmap plots.

\section{Statistical analysis}

Significant differences of the gene expression between the culture from fermentation with lactate supplementation vs. the control were determined using ANOVA in R software (version 3.5.2). TPM values were first transformed to log10-scale. The log10-transformed TPM values were then properly centered for better representation of the data using the heatmap plots. Fold changes (FCs) as the ratio of

the TPM values were calculated following the method reported by Love et al. [38], and were used to compare the differentially expressed genes (DEGs) between the culture from fermentation with lactate supplementation and the control.

\section{RNA-Seq data accession number}

The RNA-Seq sequencing data have been deposited in the NCBI Sequence Read Archive (SRA) under the accession number PRJNA564589

\section{Abbreviations}

CA: $n$-Caproic acid; DEG: differentially expressed gene; TPM: the number of transcripts per million; HPLC: high performance liquid chromatography; ABC: ATPbinding cassette; PTS: the phosphotransferase system; GO: Gene Ontology (GO); COGs: Clusters of Orthologous Groups

\section{Declaration}

\section{Authors' contributions}

YT planned and analysed the results, and wrote the manuscript. SL performed the experiments. CW participated in the planning and revision of manuscript, $\mathrm{CW}$ and QY participated in the experiments. All authors read and approved the final manuscript.

\section{Author details}

1 CAS Key Laboratory of Environmental and Applied Microbiology \& Environmental Microbiology Key Laboratory of Sichuan Province, Chengdu Institute of Biology, Chinese Academy of Sciences, Chengdu 610041, People's Republic of China. 2 Department of Biosystems

Engineering, Auburn University, Auburn, AL 36849, USA.

\section{Acknowledgements}

We thank professor Yi Wang and Jun Feng for their assistance and advice for the study.

\section{Competing interests}

The authors declare that they have no competing interests.

\section{Availability of supporting data}

The RNA-Seq sequencing data have been deposited in the NCBI Sequence Read Archive (SRA) under the accession number PRJNA564589

\section{Consent for publication}


All authors have read and approved this manuscript.

\section{Ethics approval and consent to participate}

Not applicable.

\section{Funding}

This work was financially supported by the Natural Science Foundation of China (31770090), the Open-foundation project of CAS Key Laboratory of Environmental and Applied Microbiology (KLCAS-2017-01).

\section{References}

1. Roghair M, Liu Y, Adiatma JC, Weusthuis RA, Bruins ME, Buisman CJN, Strik D: Effect of n-Caproate Concentration on Chain Elongation and Competing Processes. ACS Sustain Chem Eng 2018, 6(6):7499-7506.

2. Nzeteu CO, Trego AC, Abram F, O'Flaherty V: Reproducible, high-yielding, biological caproate production from food waste using a single-phase anaerobic reactor system. Biotechnol Biofuels 2018, 11:108.

3. Agler MT, Wrenn BA, Zinder SH, Angenent LT: Waste to bioproduct conversion with undefined mixed cultures: the carboxylate platform. Trends Biotechnol 2011, 29(2):70-78.

4. Spirito CM, Richter H, Rabaey K, Stams AJ, Angenent LT: Chain elongation in anaerobic reactor microbiomes to recover resources from waste. Curr Opin Biotechnol 2014, 27:115-122.

5. Weimer PJ, Stevenson DM: Isolation, characterization, and quantification of Clostridium kluyveri from the bovine rumen. Appl Microbiol Biot 2012, 94(2):461-466.

6. Seedorf H, Fricke WF, Veith B, Bruggemann H, Liesegang H, Strittimatter A, Miethke M, Buckel W, Hinderberger J, Li FL et al: The genome of Clostridium kluyveri, a strict anaerobe with unique metabolic features. P Natl Acad Sci USA 2008, 105(6):2128-2133.

7. Grootscholten TIM, Kinsky dal Borgo F, Hamelers HVM, Buisman CJN: Promoting chain elongation in mixed culture acidification reactors by addition of ethanol. Biomass and Bioenergy 2013, 48:10-16.

8. Roghair M, Liu Y, Strik D, Weusthuis RA, Bruins ME, Buisman CJN: Development of an Effective Chain Elongation Process From Acidified Food Waste and Ethanol Into n-Caproate. Front Bioeng Biotechnol 2018, 6:50.

9. Steinbusch KJJ, Hamelers HVM, Plugge CM, Buisman CJN: Biological formation of caproate and caprylate from acetate: fuel and chemical production from low grade biomass. Energy Environ Sci 2011, 4(1):216-224.

10. Chen WS, Ye Y, Steinbusch KJJ, Strik DPBTB, Buisman CJN: Methanol as an alternative electron donor in chain elongation for butyrate and caproate formation. Biomass Bioenerg 2016, 93:201-208.

11. Kenealy WR, Waselefsky DM: Studies on the Substrate Range of Clostridium Kluyveri the Use of Propanol and Succinate. Arch Microbio/1985, 141(3):187-194.

12. Jeon BS, Kim BC, Um Y, Sang BI: Production of hexanoic acid from D-galactitol by a newly isolated Clostridium sp. BS-1. Applied microbiology and biotechnology 2010, 88(5):1161-1167.

13. Kucek LA, Nguyen M, Angenent LT: Conversion of I-lactate into n-caproate by a continuously fed reactor microbiome. Water research 2016, $93: 163-171$.

14. Zhu X, Tao Y, Liang C, Li X, Wei N, Zhang W, Zhou Y, Yang Y, Bo T: The synthesis of n-caproate from lactate: a new efficient process for medium-chain carboxylates production. Sci Rep 2015, 5:14360.

15. Zhu X, Zhou Y, Wang Y, Wu T, Li X, Li D, Tao Y: Production of high-concentration n-caproic acid from lactate through fermentation using a newly isolated Ruminococcaceae bacterium CPB6. Biotechnol Biofuels 2017, 10:102.

16. Wang H, Li X, Wang Y, Tao Y, Lu S, Zhu X, Li D: Improvement of n-caproic acid production with Ruminococcaceae bacterium CPB6: selection of electron acceptors and carbon sources and optimization of the culture medium. Microb Cell Fact 2018, 17(1):99.

17. Tao Y, Zhu XY, Wang H, Wang Y, Li XZ, Jin H, Rui JP: Complete genome sequence of Ruminococcaceae bacterium CPB6: A newly isolated culture for efficient n-caproic acid production from lactate. J Biotechnol 2017, 259:91-94.

18. Wang Y, Li XZ, Mao YJ, Blaschek HP: Single-nucleotide resolution analysis of the transcriptome structure of Clostridium beijerinckii NCIMB 8052 using RNA-Seq. Bmc Genomics 2011, 12.

19. Sedlar K, Koscova P, Vasylkivska M, Branska B, Kolek J, Kupkova K, Patakova P, Provaznik I: Transcription profiling of butanol producer Clostridium beijerinckii NRRL B-598 using RNA-Seq. Bmc Genomics 2018, 19.

20. Wei H, Fu Y, Magnusson L, Baker JO, Maness PC, Xu Q, Yang SH, Bowersox A, Bogorad I, Wang W et al: Comparison of transcriptional profiles of Clostridium thermocellum grown on cellobiose and pretreated yellow poplar using RNA-Seq. Front Microbio/ $2014,5$.

21. Wang Y, Li XZ, Mao YJ, Blaschek HP: Genome-wide dynamic transcriptional profiling in clostridium beijerinckii NCIMB 8052 using single-nucleotide resolution RNA-Seq. Bmc Genomics 2012, 13.

22. Wang Y, Li XZ, Blaschek HP: Effects of supplementary butyrate on butanol production and the metabolic switch in Clostridium beijerinckii NCIMB 8052: genome-wide transcriptional analysis with RNA-Seq. Biotechnol Biofuels 2013, 6.

23. Patakova P, Linhova M, Rychtera M, Paulova L, Melzoch K: Novel and neglected issues of acetone-butanol-ethanol (ABE) fermentation by clostridia: Clostridium metabolic diversity, tools for process mapping and continuous fermentation systems. Biotechnology advances 2013, 31(1):58-67.

Page $13 / 19$ 
24. Jiao SY, Zhang Y, Wan CX, Lv J, Du RJ, Zhang RJ, Han B: Transcriptional analysis of degenerate strain Clostridium beijerinckii DG-8052 reveals a pleiotropic response to $\mathrm{CaCO}(3)$ associated recovery of solvent production. Sci Rep-Uk 2016, 6.

25. Lee J, Jang YS, Han MJ, Kim JY, Lee SY: Deciphering Clostridium tyrobutyricum Metabolism Based on the Whole-Genome Sequence and Proteome Analyses. Mbio 2016, 7(3).

26. Tao Y, Hu X, Zhu X, Jin H, Xu Z, Tang Q, Li X: Production of Butyrate from Lactate by a Newly Isolated Clostridium sp. BPY5. Appl Biochem Biotechnol 2016.

27. Rogatzki MJ, Ferguson BS, Goodwin ML, Gladden LB: Lactate is always the end product of glycolysis. Front Neurosci-Switz $2015,9$.

28. Skory CD: Isolation and expression of lactate dehydrogenase genes from Rhizopus oryzae. Applied and environmental microbiology 2000, 66(6):23432348.

29. Piggot PJ, Moran CPJ, Youngman P (eds.): Regulation of Bacterial Differentiation: Washington, D.C.; 1994.

30. Sauer U, Santangelo JD, Treuner A, Buchholz M, Durre P: Sigma factor and sporulation genes in Clostridium. Fems Microbiol Rev 1995, 17(3):331-340.

31. Woods DR, Jones DT: Physiological responses of Bacteroides and Clostridium strains to environmental stress factors. Adv Microb Physiol 1986, 28:1-64.

32. Hollenstein K, Dawson RJ, Locher KP: Structure and mechanism of ABC transporter proteins. Curr Opin Struct Bio/ 2007, 17(4):412-418.

33. Cui J, Davidson AL: ABC solute importers in bacteria. Essays Biochem 2011, 50(1):85-99.

34. Jones PM, George AM: The ABC transporter structure and mechanism: perspectives on recent research. Cell Mol Life Sci 2004, 61(6):682-699.

35. Jason G. McCoy, Elena J. Levin, Zhou M: Structural insight into the PTS sugar transporter ElIC. Biochim Biophys Acta 2015, 1850(3):577-585.

36. Nguyen TX, Yen MR, Barabote RD, Saier MH, Jr.: Topological predictions for integral membrane permeases of the phosphoenolpyruvate:sugar phosphotransferase system. J Mol Microbiol Biotechnol 2006, 11(6):345-360.

37. Patro R, Mount SM, Kingsford C: Sailfish enables alignment-free isoform quantification from RNA-seq reads using lightweight algorithms. Nat Biotechnol 2014, 32(5):462-U174.

38. 38. Love Ml, Huber W, Anders S: Moderated estimation of fold change and dispersion for RNA-seq data with DESeq2. Genome Biol 2014, 15(12).

\section{Figures}
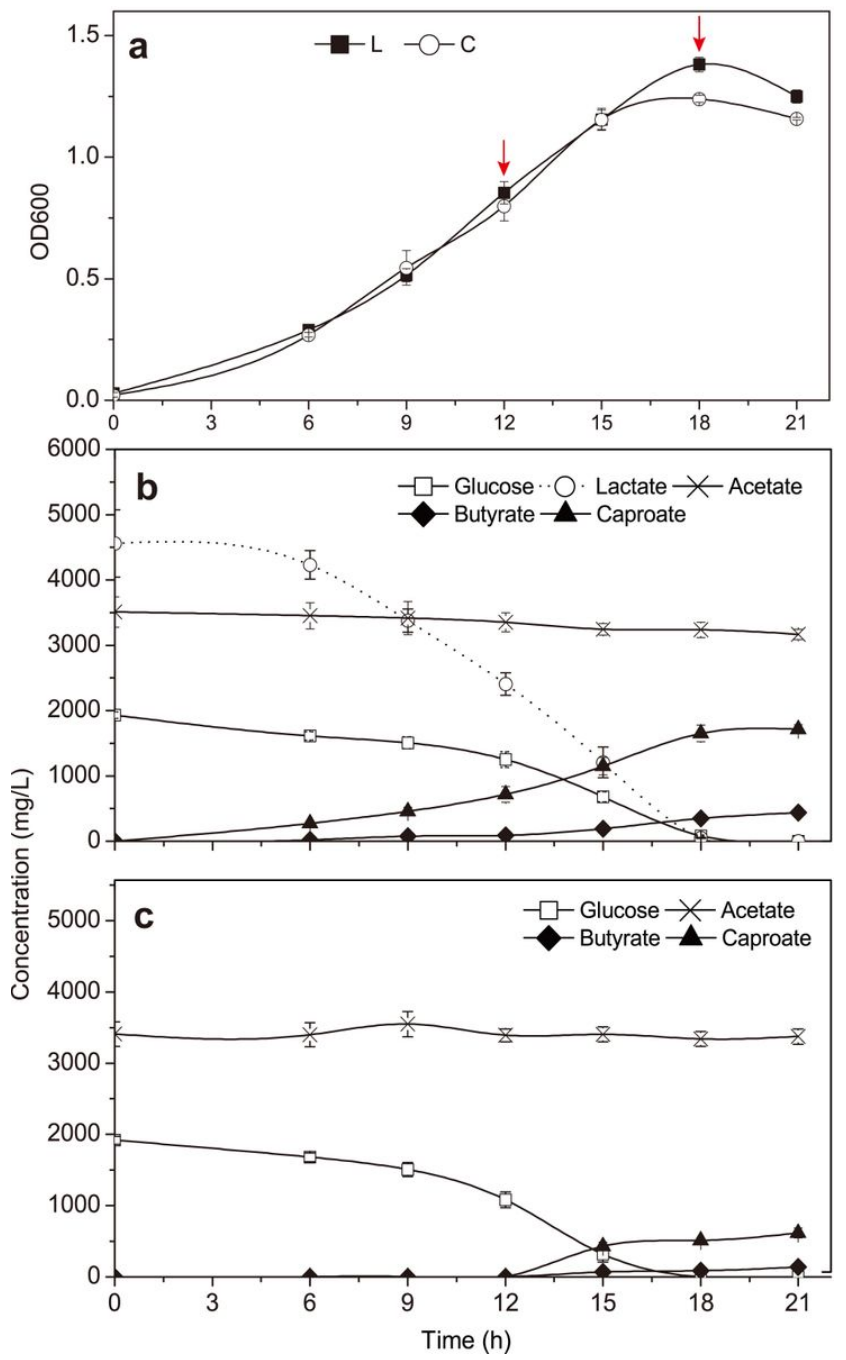

Figure 1 
Fermentation kinetics of Ruminococcaceae bacterium CPB6. (a) Cell growth profiles. Time points for taking samples subjected to RNA-Seq are indicated with red vertical arrows. L: fermentation with lactate supplementation; C: control fermentation without lactate supplementation; (b) Sugar consumption and metabolites production during the fermentation with the supplementation of lactate; (c) Sugar consumption and metabolites production during the control fermentation (without the supplementation of lactate). Values represent the mean of the biological triplicates and error bars represent the standard deviations.

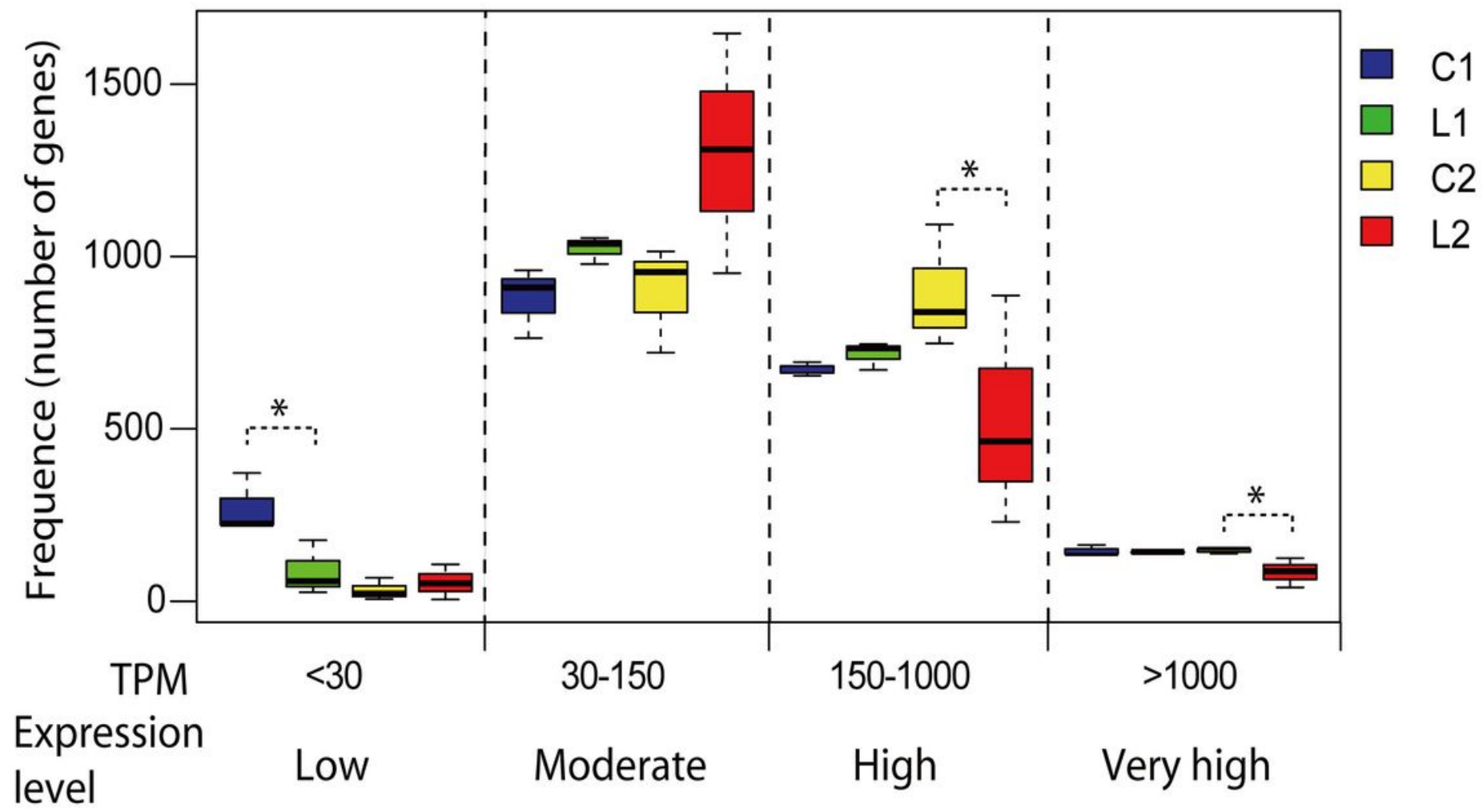

\section{Figure 2}

Frequency histogram of transcripts from the RNA-Seq results. L: cell culture with lactate supplementation; C: control culture without lactate supplementation; Number 1 and 2 represented the exponential phase and stationary phase, respectively. The diagram shows the distribution of the number of genes expressed at different transcripts per million (TPM) levels. The percentage value above each bar indicates the genes at the specific expression level accounting for the proportion of the total number of genes. The ' $*$ ' mark indicates that significantly different frequencies (i.e., numbers of genes) were observed between the two RNA-Seq data sets from lactate-supplemented fermentation $(L)$ vs. the control (C), respectively. 


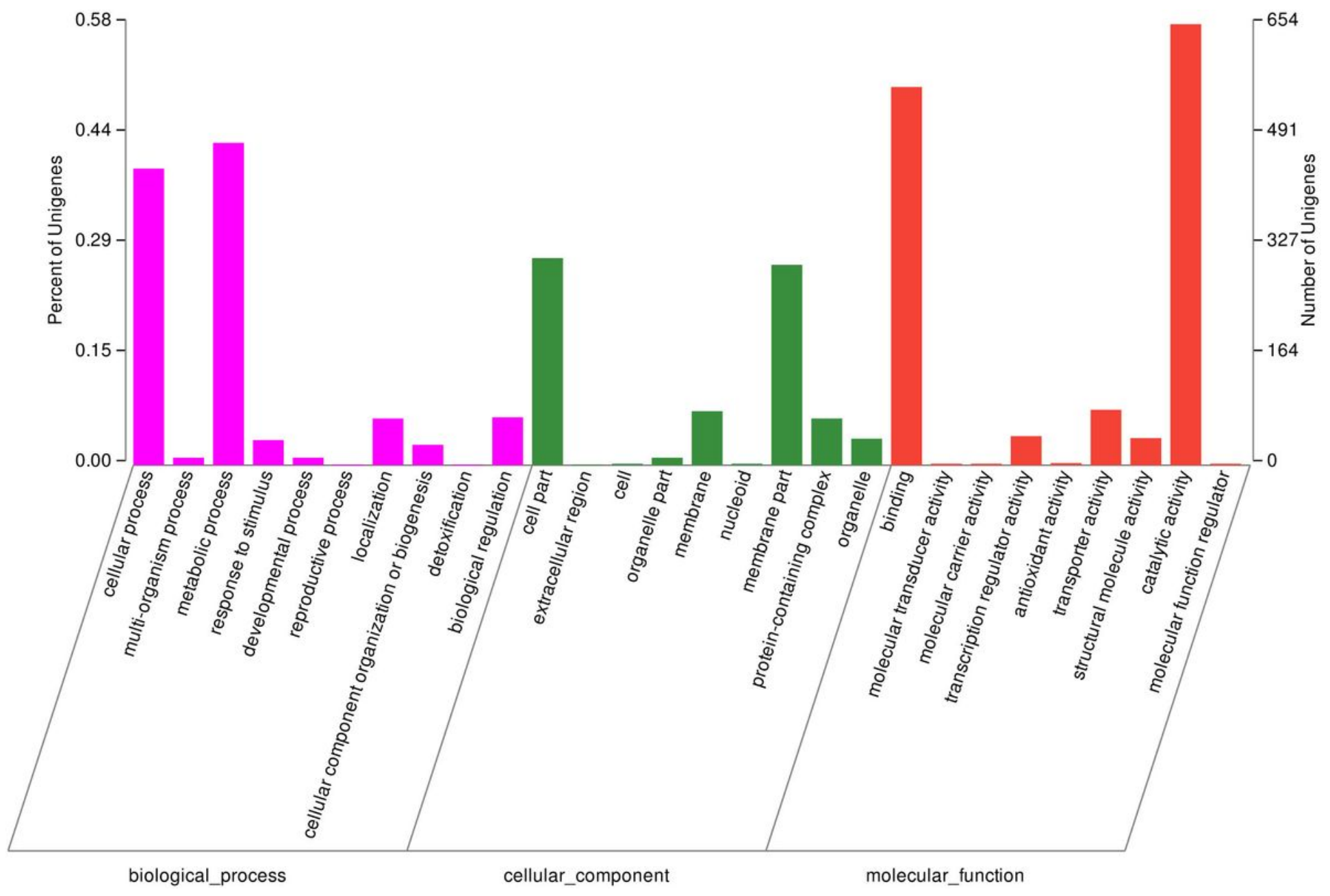

Figure 3

Annotation of genes using Gene Ontology (GO) in the transcriptome of strain CPB6. Left axis: the proportion of genes falling into each GO category; right axis: the number of genes falling into each GO category. 


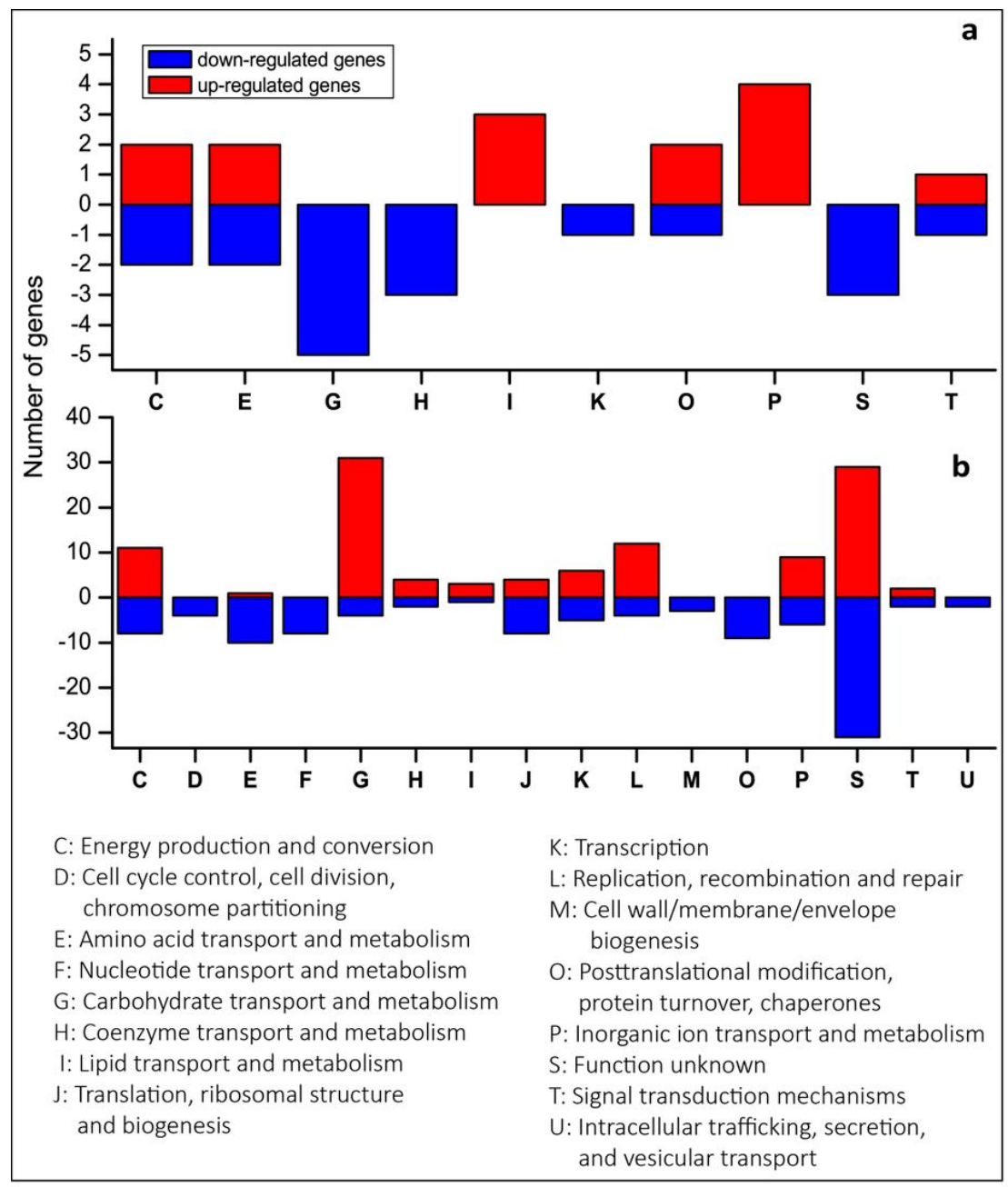

\section{Figure 4}

The number of differentially expressed genes (DEGs) between the culture with lactate supplementation and the control falling into each Clusters of Orthologous Groups (COG) categories during the exponential phase (a) and the stationary phase (b), respectively. Note that since COG categories overlap, the sum of all COG annotated genes are larger than the total number of all up- and down-regulated genes analyzed. 


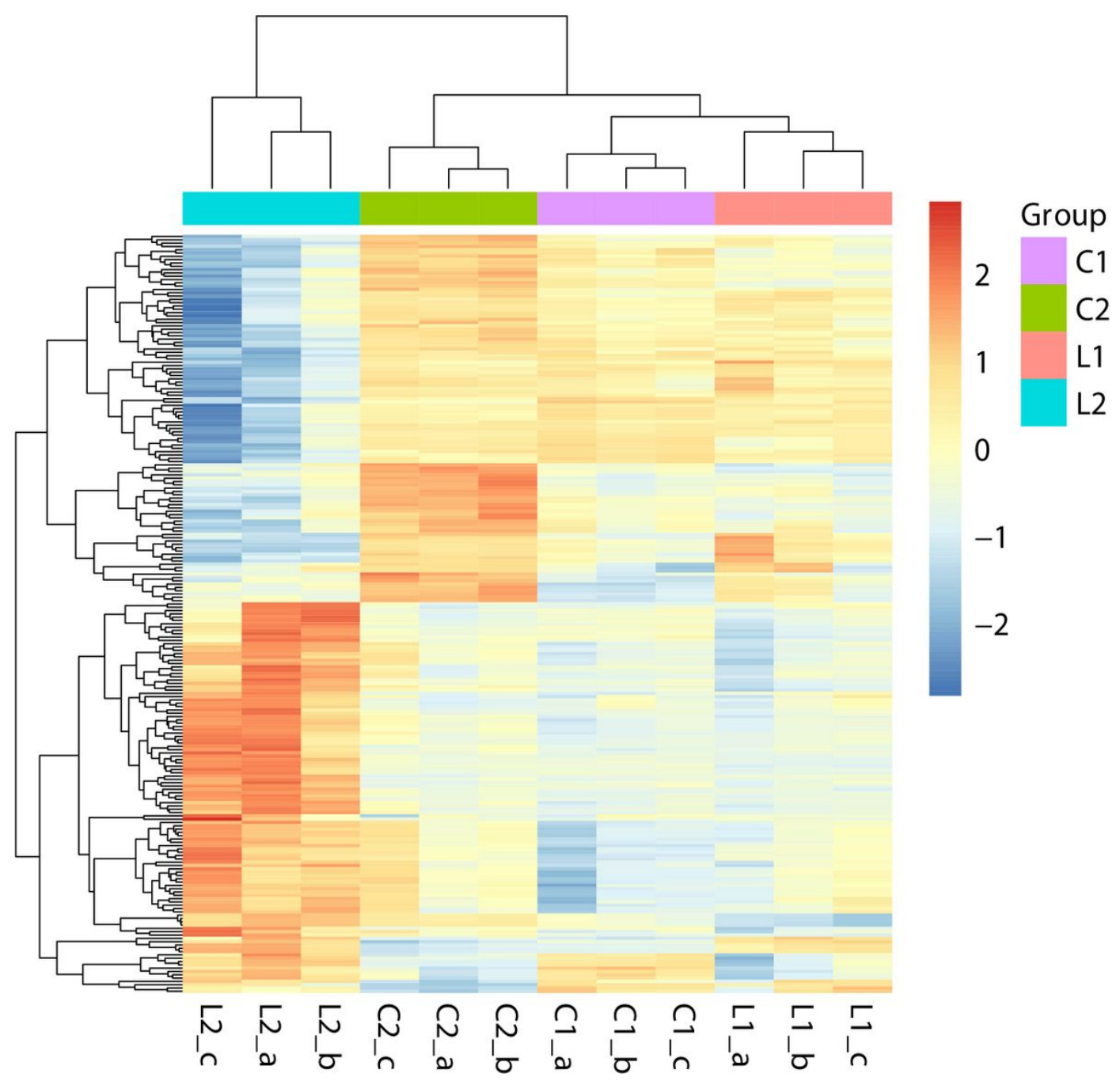

Figure 5

Clustering of differentially expressed genes (DEGs) between the culture with lactate supplementation (L) and the control (C) at the exponential and stationary phases. Values of log10TPM 


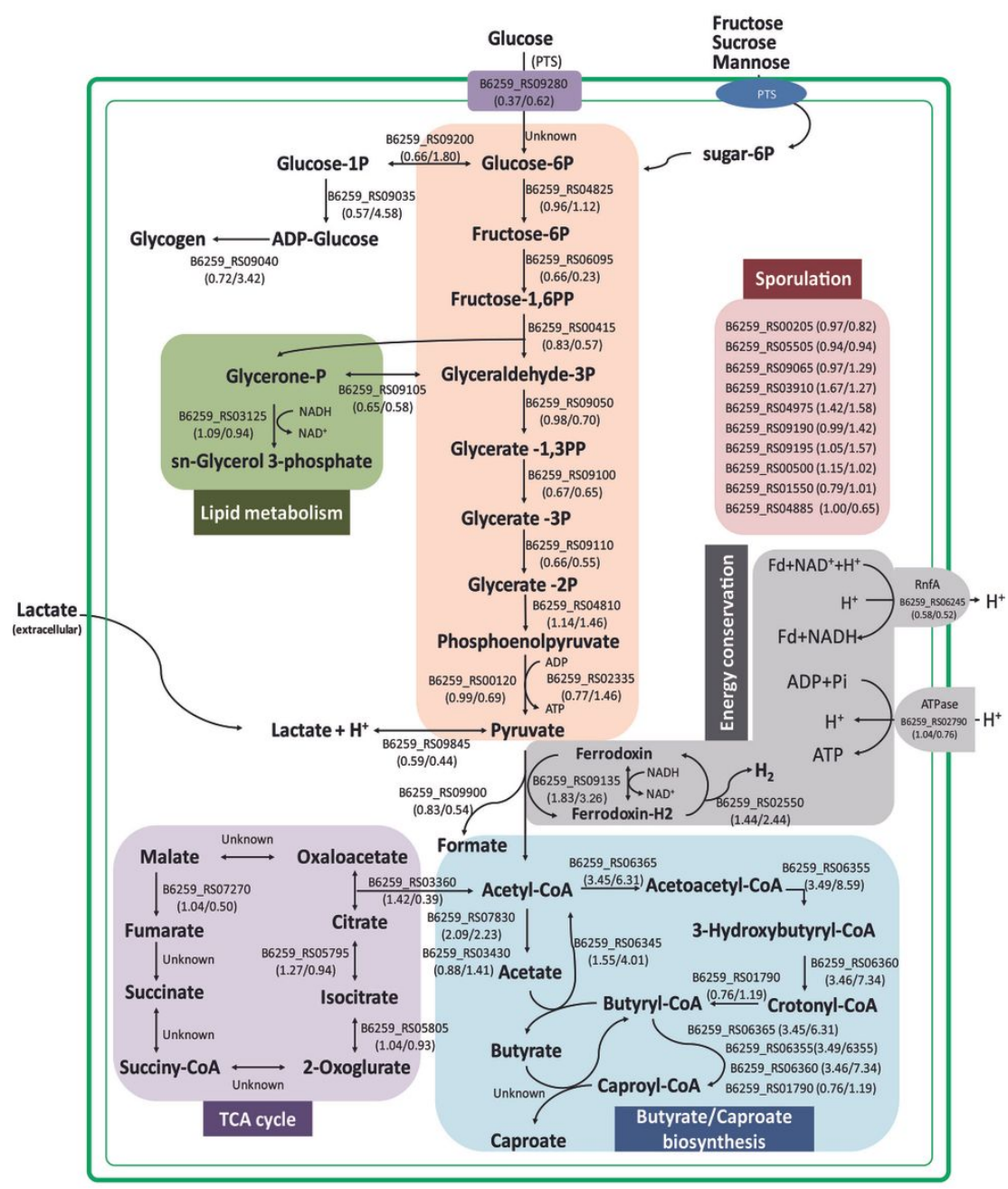

\section{Figure 6}

The overview of the central metabolic pathway in strain CPB6 with fold changes (FCs) of the expression of genes based on the RNA-Seq results. The number in parentheses represents the FC of TPM between the culture with lactate supplementation vs. the control; the first and the second numbers in the same parentheses represent the gene expression FC in the exponential and stationary phases, respectively.

\section{Supplementary Files}

This is a list of supplementary files associated with this preprint. Click to download.

- Additionalfile.pdf

- Tables2.xIsx 